Rev. Adm. Saúde (On-line), São Paulo, v. 20, n. 81: e260, jul. - set. 2020, Epub 10 dez. 2020 http://dx.doi.org/10.23973/ras.81.260

PERSPECTIVAS

\title{
Avaliação da qualidade hospitalar
}

\author{
Haino Burmester
}

1. Médico, administrador hospitalar e de sistemas de saúde. Ex-coordenador do Programa $\mathrm{CQH}$, São Paulo SP

Não é fácil avaliar a qualidade em hospitais, porque são organizações complexas, onde interagem vários grupos de interesses, paradoxalmente, às vezes, contraditórios, quando não, até conflitantes. Embora o escopo maior de recuperar a saúde dos pacientes una todos os grupos, o "como fazê-lo" às vezes os contrapõe. As características do serviço prestado dentro de um hospital, a carga emocional inerente à maioria dos atos neles praticados, fazem com que o processo de avaliação da qualidade hospitalar tenha de contemplar muitas nuances e situações imponderáveis.

Inicialmente, é preciso verificar quem garante esta qualidade; qual é o organismo certificador, selador, acreditador ou qualquer outro nome que se the queira dar. Depois, faz-se necessário conhecer quais são os critérios para a concessão deste reconhecimento, ou seja, qual a metodologia usada. Em seguida, quem aplica esta metodologia e em nome de quem se está atuando. É preciso conhecer quais as motivações das pessoas envolvidas, seus conflitos de interesse e sua conduta moral e ética pregressa. Por fim, é preciso não confundir reconhecimento da qualidade, por qualquer dos meios listados acima, com preparação ou consultoria usada antes do processo de avaliação, propriamente dito.

O que se tem visto, com muita frequência, são empresas de consultoria "preparando" organizações para o reconhecimento da qualidade que, mais tarde, elas mesmas credenciam; ou seja, preparam a organização para posteriormente elas próprias certificam como "de qualidade". Não se conhece nenhum hospital "preparado" por essas consultorias cuja "qualidade" não tenha sido reconhecida posteriormente por elas. Ora, o potencial corruptor dessa prática é evidente. Por que não considerar esse processo simplesmente como uma consultoria e ponto final? Por que travesti-la de um processo mais sofisticado do que na realidade é? Esconder-se sob o manto de certificação 
quando na verdade não passa de uma consultoria. Nada errado em se fazerem consultorias em hospitais ou qualquer outro tipo de organização; consultorias bem indicadas e bem executadas, podem ser muito uteis para as organizações. Mas, distorcendo o escopo do processo, podem acabar enganando cidadãos de boa-fé que desconhecem as nuances envolvidas e acreditam que estão diante de algo que defende seus interesses. É válido argumentar que não faz diferença se os objetivos maiores forem atingidos. Porém, será que em fazendo isso, não contribuem para aumentar a descrença das pessoas nas instituições por criar algo que não é verdadeiro, que possa parecer-se com manipulação mal intencionada?

Estas certificações, muitas vezes, são desencadeadas pela vaidade de executivos afoitos ou pelo narcisismo de parecer o melhor, sem substância para isso. Também devem-se mencionar os interesses mercadológicos para se cobrar mais por serviços, supostamente, de melhor qualidade. Nada errado com essas motivações, mas o que se argumenta aqui é que se faça isso de maneira transparente e honesta sem tergiversar sobre algo tão importante como a saúde das pessoas podendo, subliminarmente, induzir desconfiança com relação aos hospitais, com consequências indesejáveis no curto e longo prazo. Além do que, questiona-se, também, quanto destes processos estão chegando ao conhecimento dos pacientes. Será que os pacientes, os mais interessados em cuidados com qualidade sabem alguma coisa ou estão impactados por essas avaliações? Sua decisão de usar esse ou aquele serviço é influenciada por certificações de qualidade? Parece que isso não é verdadeiro em nenhum lugar onde se praticam tais avaliações.

Deve-se, portanto, ter muito cuidado com a relação comercial que se possa inserir na prestação desse serviço. Não se pode entender que alguém ganhe dinheiro para dizer que o outro é bom. Só se pode entender essa relação sem intermediação comercial. A sociedade não pode crer em processo baseado numa relação comercial que defina quem deva ser certificado. Ou o governo faz isto por meio de seus agentes de fiscalização, para garantir à um mínimo de qualidade compatível com aquilo que todos os cidadãos têm direito ou a sociedade civil organizada o faz, espontânea e voluntariamente, para garantir estes e outros direitos. Esta é a contribuição que a sociedade civil organizada deve e pode dar para o bem-estar de todos.

O Estado não pode e nem deve se encarregar de todas as ações para o bemestar da sociedade. A lei, cuja execução é prerrogativa do Estado, de certa forma, é restritiva, no sentido de delimitar o mínimo que deverá ser cumprido por todos, de maneira a que haja harmonia e equilíbrio na sociedade; ela não incentiva a excelência. A lei define o que os cidadãos não poderão deixar de fazer para conviver harmoniosamente; mas, ela não define e nem deve definir o que eles deverão fazer para serem mais felizes ou terem mais qualidade em suas vidas. A lei proíbe ao cidadão matar ou roubar, mas não se torna bom cidadão, apenas quem não mata nem rouba. Para se tornar bom cidadão, o indivíduo deve não só cumprir a lei, mas se empenhar para que todos a cumpram; é preciso que as pessoas façam algo mais do que apenas cumprir suas obrigações rotineiras, que são suficientes para manter o status quo, mas não para alcançar a excelência. 
Por isso, um processo de avaliação da qualidade hospitalar deve ser desenvolvido de maneira continuada e por organizações da sociedade civil organizada; não pode se resumir a um corte virtual da realidade dado por uma visita momentânea para a qual a organização se prepara, com ou sem ajuda externa. É preciso, portanto, que haja um acompanhamento permanente da aplicação de um modelo assistencial e de gestão, comprovado pelo constante monitoramento de indicadores e outras atividades que aproximem avaliadores e avaliados, voluntariamente, com o único desejo de fazer as coisas com mais qualidade. Esta é a forma como o Compromisso com a Qualidade Hospitalar (CQH), programa mantido desde 1991 pela Associação Paulista de Medicina (APM), para contribuir com a melhoria contínua dos hospitais em São Paulo e no Brasil, por meio de uma metodologia específica e coerente. Aliás, a ação do CQH de há muito já evoluiu de mera avaliação para o estímulo da melhoria contínua da qualidade. Esta é a forma como se pode atingir a desejada qualidade, disseminando modelos, já testados, para serem seguidos. Estimulando práticas de gestão que já tenham dado resultado e possa servir de orientação.

$\mathrm{O} C Q H$ trabalha com um modelo de gestão praticado em grandes, pequenas e médias empresas em diversos setores da economia, inclusive em serviços de saúde, no Brasil e no exterior. Este modelo se aplica a organizações públicas ou privadas. Ele é suficientemente abrangente para acomodar em seu bojo diversas tendências administrativas. É uma proposta positiva de apoio aos hospitais que queiram buscar melhoria na qualidade da prestação dos seus serviços. E o faz sem alardes nem trombeteando sua ação, mas com a certeza de que está ajudando a mudar a cultura organizacional dos hospitais no país. $O$ impacto de sua ação consistente, serena e determinada, pode ser sentido de diversas maneiras. É por isso que a APM apoia este programa, que interfere positivamente no ambiente de trabalho da maioria dos profissionais médicos ao mesmo tempo que reforça seu compromisso social.

(c) This is an Open Access article distributed under the terms of the Creative Commons Attribution License, which permits unrestricted use, distribution, and reproduction in any medium, provided the original work is properly cited 